\title{
Cardiovascular Health Behaviors and Risk Factors among Argentine and American University Students
}

\author{
Gina Fitzgerald, Gabriella Smith, Don Thompson \\ Pepperdine University, USA
}

\begin{abstract}
Article Info
ABSTRACT

Article history:

Received April 16, 2014

Revised May 20, 2014

Accepted May 29, 2014

Cardiovascular disease is the leading cause of death in adults in both the United States and Argentina. Scientific literature has consistently shown the effects of behaviors and risk factors on cardiovascular health; however, few have investigated cardiovascular behaviors and risk factors in early adulthood. We assessed the associations between main cardiovascular behaviors and cardiovascular risk factors among 594 young adults in a crosscultural analysis between the United States and Argentina through a web-

Keyword:

Cardiovascular Health

Behavior

Argentina

United States

University students based survey and vital statistics measurements. We tested our data through principle component analysis, bivariate correlations, and independent sample T-tests.After thorough analysis we saw that, cross culturally, correlations exist between cardiovascular risk factors and behaviors that are consistent in both populations. Health habit, health knowledge, health history and BMI are all significantly correlated with mean arterial pressure. T-tests showed that population groups with a higher risk factor mean also had lower behavior means, indicating that populations with poor cardiovascular behaviors correlate with an accumulation of cardiovascular risk factors. In conclusion, young adults with low prevalence of cardiovascular health behaviors have low prevalence of cardiovascular health risk factors.
\end{abstract}

Copyright (C) 2014 Institute of Advanced Engineering and Science. All rights reserved.

Corresponding Author:

Don Thompson,

Pepperdine University, USA

Email: thompson@pepperdine.edu

\section{INTRODUCTION}

Throughout much of the world, cardiovascular disease (CVD) is the leading causes of adult death [1]. In both the United States and Argentina, CVD annually accounts for over one third of adult mortality [2],[3]. Additionally, CVD is the primary cause of death among Hispanic and Latino populations in the United States [4] and this is often attributed to the low socioeconomic status held by a large proportion of these populations. Research shows that middle-age individuals with a low CVD risk profile, defined as the levels of established modifiable CVD risk factors, [5] have dramatically lower mortality rates, greater longevity, and substantially lower rates and risks for CVD events in comparison to individuals without a lowrisk profile [5]-[8]. Furthermore, a low risk profile in middle age is associated with higher quality of life and lower Medicare charges in advanced age [6],[9],[10].

There is substantial epidemiological evidence that shows that a person's risk for cardiovascular disease will be dramatically lower if he or she can maintain optimal levels of risk factors until middle age. Additionally, his or her survival will be markedly longer than that of a person who has developed one or more risk factors [11]-[13] Primary prevention is viewed as the principal mean to halt the onset of CVD, yet most studies of modifiable behaviors and CVD risk factors examine older adults and elderly, [14]-[17] while few studies have investigated behaviors and CVD risk factors in early adulthood [18]. There have been recent studies that examine, in the young adult population, the association between cardiovascular risk factors and behaviors with cardiovascular health, as measured by carotid intima thickness. Additionally, the prevalence of the ideal cardiovascular $(\mathrm{CV})$ health metric has been studied in populations around the globe, however it 
has been mostly focused on country groups that are primarily of caucasian ethnicities, such as Finland, Australia, and the United States ${ }^{[19]}$ We chose to examine a primarily caucasian population group against a primarily hispanic population group to assess whether there are differences in $\mathrm{CV}$ behaviors and risk factors between the two countries and whether the associated trends between behaviors and risk factors is a universal trend or not.

While studying in Argentina, we proposed and conducted a cross-cultural comparative study designed to evaluate ideal CV health in young adults in both the United States and Argentina by assessing the association between cardiovascular health behaviors and risk factors as a means to prevent the onset of cardiovascular disease. Ideal cardiovascular health is defined as optimal levels for four behaviors - body mass index (BMI), smoking, physical activity, and diet, and three CV risk factors - blood pressure, fasting plasma glucose, and cholesterol [19],[20] Additionally, ideal CV health has been associated with CV morbidity [21] andthe number of ideal CV health metrics is associated with lower CVD and general mortality [22],[23]. Due to the limited funding and resources available in both locations, we chose to examine one easily assessable risk factor, blood pressure, against composites of the four listed behaviors. We focused on the relationship of the risk factor and behaviors in these two populations, keeping socioeconomic status, age, and nationality in each population constant. We hypothesized that the poor CV behaviors would be associated with poor CV risk factors. Additionally, we hypothesized that the relationship between risk factors and behaviors is homogeneous in both countries.

\section{RESEARCH METHOD}

In the fall of 2011,students at Pepperdine University, in Malibu, California, were invited to participate in an IRB sanctioned, voluntary web-based survey. Also in the fall of 2011, students at Universidad Católica de Argentina (UCA), in Buenos Aires, Argentina, were invited by a team of cardiology residents and a Pepperdine research student to participate in the same research project. A data collection station was set up at UCA School of Medicine while residents and the researcher invited Argentine students to voluntarily participate study, using a hard copy of the web based surveythat had been translated into Spanish. After the students completed the survey, the residents and the student research, under the supervision of the attending cardiologist, collected the students' data.

The web-basedsurvey assessed student development in the areas of current medical information, personal health history, family health history, personal habits, and knowledge of cardiovascular health. The survey assessed demographic information as well. The survey included 35 items, exclusive of the demographic questions, to be answered by the participant, as well as 11 items to be measured by the study administrator to assess the students' current cardiovascular health. Participants responded to 27 yes or no questions, and 8 fill in the blanks.

A Spanish paper copy of the web based survey was created for the research group in Buenos Aires, Argentina. The survey was created by an Argentine cardiologist with the assistance of the student researcher in Argentina. The context of the consent form and all survey questions remained the same between the English web survey and the Spanish paper survey, as outlined below.

1. Demographic Form:Demographic information was collected by means of a self-report document in which participants were asked their age, sex, class standing, college major, ethnicity, and campus mailbox and email address (for Pepperdine students only, as a means of receiving the participation gift card).

2. Personal Health History:Information was self reported and consisted of 11 items categorized under blood pressure, dyslipidemia, and diabetes.

3. Health History of Parents:Participants were provided a list of 6 conditions contributing to cardiovascular health, and were asked to identify those that their parents have or have not suffered from, or if the student does not know.

4. Personal Habits: Participants self reported their weekly habits. The section consisted of 17 items examining patterns in sleep, smoking, diet, and exercise.

5. Knowledge:Participants were asked3 comprehensive questionsto assess their knowledge of cardiovascular health and risk factors. In each question participants will be presented with a list and asked to identify various parts. For example, "Given the following 11 risk factors, identify the 4 that are most directly correlated with cardiovascular disease."

6. Current Medical Information: After completing the survey, Pepperdine students were invited to join researchers outside of the Pepperdine Waves Café between the hours of 12:00-16:00. There the students' heart rate and blood pressure were taken by a survey administer (supervised by a certified nurse's assistant) and recorded alongside their survey results. Students who had not taken the survey were invited to complete the survey on paper and have their vitals taken upon immediate completion. In Buenos Aires,

IJPHS Vol. 3, No. 2, June 2014 : 117 - 128 
the cardiologists and student researcher set up a data collection area in the UCA School of Medicine plaza. Students were approached and invited to participate in the survey and have their vital statistics measured.

Blood pressure was measured using an automated sphygmomanometer device (Omron, model HEM-705CP, Omron Healthcare Inc., USA). The blood pressure cuff was placed around the right upper arm. Systolic and diastolic blood pressures were measured by the blood pressure cuff as well as heart rate. Three baseline BP readings were taken at 2-min intervals by one of the investigators, while another investigator chatted amicably with the subject to dispel nervousness. An average of the 3 measurements was used for analysis. The average systolic and average diastolic values were used to calculate the mean arterial pressure by the formula: MAP $=[(2 x$ Diastolic Avg. $)+($ Systolic Avg. $)] / 3$

Height and weight values were self reported by the participants as they were not comfortable having these measurements in public. The values were reported in inches and pounds, respectively, and both were later converted to centimeters and kilograms, respectively, during data scrubbing and analysis and were used to calculate the individuals BMI, using the formula: weight $(\mathrm{kg}) /[\text { height }(\mathrm{m})]^{2}$

After taking the survey, UCA students had their height, weight, blood pressure, and heart rate measured. A portable stadiometer was used to measure height in centimeters, and a portable digital weigh scale was used to measure weight in kilograms. An Omron HEM 629 wrist blood pressure monitor was use to collect the participants resting blood pressure and resting heart rate. Three measurements were taken of both the participants blood pressure and heart rate. An average of the three measurements for both blood pressure and heart was used for analysis.

\section{RESULTS AND ANALYSIS}

Participants were surveyed once, and data was analyzed using SPSS. Over 1,000 students were invited to participate in this research study. After a process of data scrubbing, 594 participants were eligible for analysis. The data scrubbing process included deleting data of participants not born in either USA or Argentina, purging subjects with incomplete surveys, and eliminating survey responses from students who did not have their vital statistics (heart rate and blood pressure) measured. As a result, we were able to record results as follows: Argentine sample size $=399$, female subsample size $=241$, male subsample size $=158$; USA sample size $=195$, female subsample Size $=101$, male subsample size $=94$. We organized our survey and vital statistics measurements into eight variables. Although heart rate in literature is not considered a cardiovascular behavior or risk factor, it was included in our study to investigate the possibility of heart rate being a factor of cardiovascular health, since it is so closely related with the functioning of the cardiovascular system.

1) Body Mass Index (BMI): Target BMI range is $18.50-24.99 \mathrm{~kg} / \mathrm{m}^{2}$

2) Mean Arterial Pressure (MAP): Target value is $90 \mathrm{mmHg}$

3) Resting Pulse: Target value is $80 \mathrm{bpm}$

4) Country: Argentina $=1, \mathrm{USA}=2$

5) Gender: Female $=1$, Male $=2$

6) Health History Score: a composite score equal to the sum of the following binary scores (No $=1$, Yes $=$ 2) based on family health history: high cholesterol, diabetes, coronary artery disease, heart failure, stroke, and lower limb artery disease.

7) Health Knowledge Score: a composite score equal to the sum of the following binary scores (incorrect knowledge $=1$, correct knowledge $=2$ ) based on individual's knowledge that: diabetes causes CVD, high cholesterol causes CVD, smoking causes hypertension, smoking causes myocardial infarction, smoking causes stroke, and smoking causes CVD.

8) Health Habit Score: a composite score equal to the sum of binary scores $($ No $=1$, Yes $=2)$ based on the following personal health habits: fast food consumer, participant regular exercise, daily consumer of two or more fruit \& vegetable items, daily consumer of diet soda, daily consumer of soda, former smoker, and current smoker. 


\subsection{Principal Component Analysis}

\begin{tabular}{|l|r|r|r|}
\hline \multicolumn{1}{|c|}{ Component } & \multicolumn{3}{c|}{ Initial EigenValues } \\
\hline BMI & 2.035 & 25.441 & 25.441 \\
\hline MAP & 1.558 & 19.469 & 44.910 \\
\hline Pulse & 1.053 & 13.167 & 58.077 \\
\hline Country & 0.893 & 11.167 & 69.245 \\
\hline Gender & 0.840 & 10.503 & 79.748 \\
\hline Health History Score & 0.653 & 8.164 & 87.912 \\
\hline Health Knowledge Score & 0.603 & 7.534 & 95.446 \\
\hline Health Habit Score & 0.364 & 4.554 & 100.000 \\
\hline
\end{tabular}

Figure 1: Principal Component Analysis

Given the number of indicators in our data set, we began our analysis by conducting principle component analysis (PCA) to determine how variation in this ensemble of variables may best be explained. Our PCA reveals that three variables from our sample explain over $58 \%$ of sample variation. These are BMI, MAP, and pulse. In addition, $21 \%$ of variation is due to contributions made by the country in which a subject was studying and gender (Figure 1). The remaining variation is attributable to self reported personal health information. The principal components themselves and personal health history belong to the list of 7 indicators of $\mathrm{CV}$ health as identified by the American Heart Association. ${ }^{[17]}$ These 7 indicators are comprised of 3 risk factors: blood pressure, fasting plasma glucose, and cholesterol, and 4 behaviors: BMI, smoking, physical activity, and diet. Moreover, because we gathered data in two countries and across both sexes and because we wish to help subjects increase their understanding of CVD risk - prompting our desire to capture CVD knowledge, we included several questions about general CVD knowledge. As a result of the principal component analysis, we measured the bivariate correlation of these 28 pairs of variables, giving us the correlation matrix depicted in in Figure 1. In addition, we captured the PCA variance analysis as shown in Figure 2. From these we can see that the most critical variables that contribute to the variation in the data are, in decreasing order of importance - BMI, MAP, and pulse. Therefore, in our modeling of data, we have focused on determining the ways that variables 4-8 drive the first three variables.

Our underlying hypothesis is that each of the variables - BMI, MAP, and pulse - are negatively correlated with health history, knowledge, and health habit. However, because BMI is a CV behavior while MAP is a CV risk factor we predicted that BMI and MAP are pairwise positively correlated. Pulse is unknown to be either a behavior or risk factor but because it is one of the principal variables of variation along with BMI and MAP, we predicted that pulse is also positively correlated with both BMI and MAP. The correlations in Figure 2 largely confirm our hypotheses, with the exception of pulse vs BMI and health history, both of which require further investigation. Further analysis of the correlation by gender and country revealed that the only significant value is female argentine students, for whom BMI vs. pulse correlates as 0.115 with p-value 0.095 . As for pulse vs. health history, we carried out gender and country controlled analysis and we discovered that the only significant correlation belongs to those students who are male Argentines. The correlation was 0.137 with significance of 0.086 . This too requires further research, as planned for our next study. 


\subsection{Overall Correlations}

\begin{tabular}{|c|c|c|c|c|c|c|c|}
\hline \multicolumn{2}{|c|}{ Overall Correlations } & MAP & BMI & Pulse & $\begin{array}{l}\text { Health Habit } \\
\text { Score }\end{array}$ & $\begin{array}{l}\text { Health History } \\
\text { Score }\end{array}$ & Knowledge Score \\
\hline \multirow{6}{*}{ Correlation } & MAP & 1.000 & 0.290 & 0.053 & -0.088 & -0.113 & -0.148 \\
\hline & BMI & & 1.000 & -0.115 & -0.137 & -0.046 & -0.018 \\
\hline & Pulse & & & 1.000 & -0.079 & 0.089 & -0.024 \\
\hline & $\begin{array}{l}\text { Health Habit } \\
\text { Score }\end{array}$ & & & & 1.000 & 0.162 & 0.139 \\
\hline & $\begin{array}{l}\text { Health History } \\
\text { Score }\end{array}$ & & & & & 1.000 & 0.109 \\
\hline & Knowledge Score & & & & & & 1.000 \\
\hline \multirow{6}{*}{ Signifiance } & MAP & - & 0.000 & 0.098 & 0.016 & 0.003 & 0.000 \\
\hline & BMI & & . & 0.003 & 0.000 & 0.130 & 0.327 \\
\hline & Pulse & & & - & 0.028 & 0.015 & 0.276 \\
\hline & $\begin{array}{l}\text { Health Habit } \\
\text { Score }\end{array}$ & & & & - & 0.000 & 0.000 \\
\hline & $\begin{array}{l}\text { Health History } \\
\text { Score }\end{array}$ & & & & & - & 0.004 \\
\hline & Knowledge Score & & & & & & . \\
\hline
\end{tabular}

Figure 2: Overall Correlations among Survey Variables

From Figure 2 it can be seen that MAP and BMI are significantly positively correlated by a factor of 0.290 in the combined American and Argentine population. This implies that as a person's BMI increases, so does their mean arterial pressure. Pulse and BMI are significantly negatively correlated by a factor of -0.115 . This implies that as a person's BMI increases, their heart rate decreases. BMI and the health habit composite score are significantly negatively correlated by a factor of -0.137 . This implies that as the health habit composite score decreases, their BMI increases. To understand this correlation, it is important to note that a low health habit score indicates poor habits such as smoking, not eating daily fruits and vegetables, and not exercising properly. Thus having unhealthy habits is correlated to an increase in a person's BMI.

MAP and the health history composite score are significantly negatively correlated by a factor of 0.113. This implies that as the health history composite score decreases, the mean arterial pressure increases (Figure 2). To understand this correlation, it is important to note that a low health history score indicates poor family cardiovascular health such as parents who have heart failure, diabetes, high cholesterol, etc. Thus having poor family health history is correlated to an increase in a person's MAP. This is a trend that expands across both American and Argentine populations. MAP and health knowledge composite score are significantly negatively correlated by a factor of -0.148 . This implies that as the health knowledge composite score decreases, mean arterial pressure increases. To understand this correlation, it is important to note that a low health knowledge score indicates the individual knows less about cardiovascular health (such as not knowing that smoking or high cholesterol is linked to cardiovascular disease,etc). Thus having poor health knowledge is correlated to an increase in a person's MAP. This is a trend that expands across both American and Argentine populations.

\subsection{Correlation American Males}

\begin{tabular}{|c|c|c|c|c|c|c|c|}
\hline \multicolumn{2}{|c|}{ US MALE } & \multirow{2}{*}{$\frac{\text { MAP }}{1.000}$} & \multirow{2}{*}{$\frac{\text { BMI }}{0.224}$} & \multirow{2}{*}{$\begin{array}{l}\text { Pulse } \\
0.005\end{array}$} & \multirow{2}{*}{$\begin{array}{l}\text { Health Habit } \\
\text { Score } \\
-0.079\end{array}$} & \multirow{2}{*}{$\begin{array}{c}\begin{array}{c}\text { Health History } \\
\text { Score }\end{array} \\
-0.049\end{array}$} & \multirow{2}{*}{\begin{tabular}{|c|} 
Knowledge Score \\
-0.136 \\
\end{tabular}} \\
\hline \multirow{6}{*}{ Correlation } & MAP & & & & & & \\
\hline & BMI & & 1.000 & -0.089 & 0.035 & 0.043 & 0.079 \\
\hline & Pulse & & & 1.000 & -0.077 & 0.099 & 0.006 \\
\hline & $\begin{array}{l}\text { Health Habit } \\
\text { Score }\end{array}$ & & & & 1.000 & 0.006 & -0.056 \\
\hline & $\begin{array}{l}\text { Health History } \\
\text { Score }\end{array}$ & & & & & 1.000 & -0.175 \\
\hline & Knowledge Score & & & & & & 1.000 \\
\hline \multirow{6}{*}{ Signifiance } & MAP & . & 0.031 & 0.965 & 0.452 & 0.640 & 0.195 \\
\hline & BMI & & . & 0.396 & 0.739 & 0.681 & 0.450 \\
\hline & Pulse & & & . & 0.465 & 0.347 & 0.951 \\
\hline & $\begin{array}{l}\text { Health Habit } \\
\text { Score }\end{array}$ & & & & - & 0.952 & 0.592 \\
\hline & \begin{tabular}{|l|} 
Health History \\
Score
\end{tabular} & & & & & - & 0.094 \\
\hline & Knowledge Score & & & & & & . \\
\hline
\end{tabular}

Figure 3: American Male Correlations among Survey Variables 
From Figure 3 it can be seen that MAP and BMI are significantly positively correlated by a factor of 0.224 in American males. This implies that as a person's BMI increases, so does their mean arterial pressure.

\subsection{Correlation Argentine Males}

\begin{tabular}{|c|c|c|c|c|c|c|c|}
\hline \multicolumn{2}{|c|}{ ARGENTINE MALE } & MAP & BMI & Pulse & $\begin{array}{c}\text { Health Habit } \\
\text { Score }\end{array}$ & $\begin{array}{l}\text { Health History } \\
\text { Score }\end{array}$ & \\
\hline \multirow{6}{*}{ Correlation } & MAP & 1.000 & 0.227 & 0.118 & 0.063 & 0.103 & 0.149 \\
\hline & BMI & & 1.000 & 0.044 & -0.107 & 0.021 & 0.017 \\
\hline & Pulse & & & 1.000 & -0.029 & 0.137 & -0.144 \\
\hline & $\begin{array}{l}\text { Health Habit } \\
\text { Score }\end{array}$ & & & & 1.000 & 0.070 & -0.025 \\
\hline & $\begin{array}{l}\text { Health History } \\
\text { Score }\end{array}$ & & & & & 1.000 & 0.019 \\
\hline & Knowledge Score & & & & & & 1.000 \\
\hline \multirow{6}{*}{ Signifiance } & MAP & . & 0.004 & 0.140 & 0.430 & 0.199 & 0.063 \\
\hline & BMI & & . & 0.585 & 0.182 & 0.795 & 0.832 \\
\hline & Pulse & & & - & 0.718 & 0.086 & 0.070 \\
\hline & $\begin{array}{l}\text { Health Habit } \\
\text { Score }\end{array}$ & & & & - & 0.385 & 0.753 \\
\hline & $\begin{array}{l}\text { Health History } \\
\text { Score }\end{array}$ & & & & & - & 0.815 \\
\hline & Knowledge Score & & & & & & . \\
\hline
\end{tabular}

Figure 4: Argentine Male Correlations among Survey Variables

From Figure 4 it can be seen that MAP and BMI are significantly positively correlated by a factor of 0.227 in Argentine males. This implies that as a person's BMI increases, so does their mean arterial pressure.

\subsection{Correlation American Females}

\begin{tabular}{|c|c|c|c|c|c|c|c|}
\hline \multicolumn{2}{|c|}{ US FEMALE } & \multirow{2}{*}{$\frac{\text { MAP }}{1.000}$} & \multirow{2}{*}{$\begin{array}{c}\text { BMI } \\
0.143\end{array}$} & \multirow{2}{*}{$\begin{array}{c}\text { Pulse } \\
0.184\end{array}$} & \multirow{2}{*}{$\begin{array}{c}\begin{array}{c}\text { Health Habit } \\
\text { Score }\end{array} \\
0.047\end{array}$} & \multirow{2}{*}{$\begin{array}{c}\begin{array}{c}\text { Health History } \\
\text { Score }\end{array} \\
-0.103\end{array}$} & \multirow{2}{*}{$\begin{array}{c}\begin{array}{c}\text { Knowledge } \\
\text { Score }\end{array} \\
0.021\end{array}$} \\
\hline \multirow{6}{*}{ Correlation } & MAP & & & & & & \\
\hline & BMI & & 1.000 & -0.045 & -0.197 & 0.027 & 0.018 \\
\hline & Pulse & & & 1.000 & -0.052 & 0.157 & -0.054 \\
\hline & $\begin{array}{c}\text { Health Habit } \\
\text { Score }\end{array}$ & & & & 1.000 & 0.049 & 0.030 \\
\hline & $\begin{array}{l}\text { Health History } \\
\text { Score }\end{array}$ & & & & & 1.000 & -0.031 \\
\hline & $\begin{array}{c}\text { Knowledge } \\
\text { Score }\end{array}$ & & & & & & 1.000 \\
\hline \multirow{6}{*}{ Signifiance } & MAP & - & 0.152 & 0.068 & 0.640 & 0.305 & 0.836 \\
\hline & BMI & & - & 0.655 & 0.049 & 0.786 & 0.859 \\
\hline & Pulse & & & - & 0.606 & 0.120 & 0.593 \\
\hline & $\begin{array}{l}\text { Health Habit } \\
\text { Score }\end{array}$ & & & & - & 0.628 & 0.764 \\
\hline & $\begin{array}{l}\text { Health History } \\
\text { Score }\end{array}$ & & & & & $\cdot$ & 0.760 \\
\hline & $\begin{array}{l}\text { Knowledge } \\
\text { Score }\end{array}$ & & & & & & - \\
\hline
\end{tabular}

Figure 5: American Female Correlations among Survey Variables

From Figure 5 it can be seen that BMI and health habit are significantly negatively correlated by a factor of 0.197 in American females. This implies that as a person's health habits get worse (composite score decreases), their BMI increases. 


\subsection{Correlation Argentine Females}

\begin{tabular}{|c|c|c|c|c|c|c|c|}
\hline \multicolumn{2}{|c|}{ ARGENTINE FEMALE } & MAP & BMI & Pulse & $\begin{array}{l}\text { Health Habit } \\
\text { Score }\end{array}$ & $\begin{array}{l}\text { Health History } \\
\text { Score }\end{array}$ & Knowledge Score \\
\hline \multirow{6}{*}{ Correlation } & MAP & 1.000 & 0.198 & 0.146 & 0.085 & -0.106 & 0.058 \\
\hline & BMI & & 1.000 & -0.108 & -0.162 & -0.036 & 0.039 \\
\hline & Pulse & & & 1.000 & -0.122 & 0.034 & 0.032 \\
\hline & $\begin{array}{l}\text { Health Habit } \\
\text { Score }\end{array}$ & & & & 1.000 & 0.080 & -0.048 \\
\hline & $\begin{array}{l}\text { Health History } \\
\text { Score }\end{array}$ & & & & & 1.000 & -0.026 \\
\hline & Knowledge Score & & & & & & 1.000 \\
\hline \multirow{6}{*}{ Signifiance } & MAP & . & 0.002 & 0.023 & 0.189 & 0.101 & 0.371 \\
\hline & BMI & & . & 0.095 & 0.012 & 0.580 & 0.542 \\
\hline & Pulse & & & - & 0.058 & 0.598 & 0.625 \\
\hline & $\begin{array}{l}\text { Health Habit } \\
\text { Score }\end{array}$ & & & & 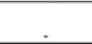 & 0.218 & 0.460 \\
\hline & $\begin{array}{l}\text { Health History } \\
\text { Score }\end{array}$ & & & & & & 0.692 \\
\hline & Knowledge Score & & & & & & - \\
\hline
\end{tabular}

Figure 6: Argentine Female Correlations among Survey Variables

From Figure 6, it can be seen that MAP and BMI are significantly positively correlated by a factor of 0.198 in Argentine females. MAP and pulse are significantly positively correlated by a factor of 0.146 . BMI is significantly negatively correlated with health habits by a factor of -0.162 , implying that as healthy habits increase, BMI decreases.

\subsection{Independent T-Tests}

To dig deeper into the relationship between the main CV risk factor and the four behaviors, we begin by considering a comparison of the means of the five factors as a function of the two countries, controlling for gender. We present these results in Figures 8 and 10 below. Figure 8 shows the results for female subjects, whereas Figures 10 details the results for male subjects.

\subsubsection{Argentina vs. American Females}

\begin{tabular}{|c|c|c|c|c|}
\cline { 2 - 5 } \multicolumn{1}{c|}{} & Country & $\mathrm{N}$ & Mean & Std. Deviation \\
\hline \multirow{2}{*}{ MAP } & 1 & 241 & 88.690 & 7.183 \\
\cline { 3 - 5 } & 2 & 101 & 84.930 & 7.847 \\
\hline \multirow{2}{*}{ BMI } & 1 & 241 & 21.840 & 2.923 \\
\cline { 3 - 5 } & 2 & 101 & 22.040 & 2.596 \\
\hline \multirow{2}{*}{ Pulse } & 1 & 241 & 77.770 & 12.672 \\
\cline { 3 - 5 } & 2 & 99 & 78.600 & 13.570 \\
\hline \multirow{2}{*}{ Health Habit Score } & 1 & 241 & 11.000 & 1.334 \\
\hline \multirow{2}{*}{ Health History } & 2 & 101 & 12.170 & 1.393 \\
\hline Score & 1 & 241 & 10.510 & 1.706 \\
\hline \multirow{2}{*}{ Knowledge Score } & 1 & 101 & 11.120 & 1.321 \\
\cline { 2 - 5 } & 2 & 241 & 9.490 & 1.403 \\
\cline { 2 - 5 } & 2 & 101 & 12.160 & 2.682 \\
\hline
\end{tabular}

Figure 7: Female Group Statistics

\begin{tabular}{|c|c|c|c|c|c|}
\cline { 2 - 6 } \multicolumn{1}{c|}{} & \multicolumn{5}{c|}{ Females: $\mathrm{t}$-test for Equality of Means } \\
\cline { 2 - 6 } \multicolumn{1}{c|}{} & $\mathrm{t}$ & $\mathrm{df}$ & $\begin{array}{c}\text { Significance (2- } \\
\text { tailed) }\end{array}$ & Mean Differences & $\begin{array}{c}\text { Std. Error } \\
\text { Differences }\end{array}$ \\
\hline MAP & 4.297 & 340 & 0.000 & 3.761 & 0.875 \\
\hline BMI & -0.605 & 340 & 0.546 & -0.203 & 0.336 \\
\hline Pulse & -0.534 & 338 & 0.594 & -0.824 & 1.545 \\
\hline $\begin{array}{c}\text { Health Habit } \\
\text { Score }\end{array}$ & -7.266 & 340 & 0.000 & -1.164 & 0.160 \\
\hline $\begin{array}{c}\text { Health History } \\
\text { Score }\end{array}$ & -3.182 & 340 & 0.000 & -0.604 & 0.190 \\
\hline Knowledge Score & -12.026 & 340 & 0.000 & -2.669 & 0.222 \\
\hline
\end{tabular}

Figure 8: Female T-Tests 
From Figures 7 and 8, it is evident that there is a significant difference in the between the means of the mean arterial pressure of the Argentine and American female populations. As T1 (from the T-test formula) representsArgentine females and T2 American females, it can be noted that Argentine female population has a significantly larger mean, mean arterial pressure (Figure 7). Additionally, there are significant differences in the mean habit, health and knowledge scores between the Argentine and American female populations (Figure 8). Once again, the Argentine female population has significantly lower means in habit, health and knowledge scores. These low mean scores correspond to poorer health habits, health history, and health knowledge. From these two pieces of evidence, it can be inferred that populations with significantly poorer health habits, history and knowledge will have significantly higher mean arterial pressure. Thus prevalence of poor cardiovascular health behaviors corresponds to poor cardiovascular disease risk factor.

\subsubsection{Argentina vs. American Males}

\begin{tabular}{|c|c|c|c|c|}
\cline { 2 - 5 } \multicolumn{1}{c|}{} & Country & $\mathrm{N}$ & Mean & Std. Deviation \\
\hline \multirow{2}{*}{ MAP } & 1 & 158 & 95.400 & 8.586 \\
\cline { 3 - 5 } & 2 & 93 & 87.000 & 10.444 \\
\hline \multirow{2}{*}{$\mathrm{BMI}$} & 1 & 158 & 27.390 & 3.010 \\
\cline { 3 - 5 } & 2 & 93 & 23.120 & 2.733 \\
\hline \multirow{2}{*}{ Pulse } & 1 & 158 & 72.600 & 12.390 \\
\cline { 3 - 5 } & 2 & 92 & 70.920 & 11.618 \\
\hline \multirow{2}{*}{ Health Habit Score } & 1 & 158 & 10.870 & 1.376 \\
\hline \multirow{2}{*}{ Health History } & 2 & 93 & 12.300 & 1.196 \\
\hline Score & 1 & 158 & 9.970 & 2.426 \\
\hline \multirow{2}{*}{ Knowledge Score } & 2 & 93 & 11.410 & 0.797 \\
\hline & 2 & 158 & 9.310 & 1.432 \\
\hline
\end{tabular}

Figure 9: Male Group Statistics

\begin{tabular}{|c|c|c|c|c|c|}
\hline & \multicolumn{5}{|c|}{ Males: t-test for Equality of Means } \\
\hline & $\mathrm{t}$ & $\mathrm{df}$ & $\begin{array}{l}\text { Significance (2- } \\
\text { tailed) }\end{array}$ & Mean Differences & $\begin{array}{c}\text { Std. Error } \\
\text { Differences }\end{array}$ \\
\hline MAP & 6.900 & 249 & 0.000 & 8.401 & 1.218 \\
\hline BMI & 3.343 & 249 & 0.001 & 1.272 & 0.380 \\
\hline Pulse & 1.026 & 248 & 0.306 & 1.677 & 1.635 \\
\hline $\begin{array}{l}\text { Health Habit } \\
\text { Score }\end{array}$ & -8.322 & 249 & 0.000 & -1.428 & 0.172 \\
\hline $\begin{array}{l}\text { Health History } \\
\text { Score }\end{array}$ & -5.524 & 249 & 0.000 & -1.434 & 0.260 \\
\hline Knowledge Score & -8.681 & 249 & 0.000 & -2.184 & 0.252 \\
\hline
\end{tabular}

Figure 10: Male T-Tests

From Figures 9 and 10 it is evident that there is a significant difference between the means of the mean arterial pressure and the mean BMI of the Argentine and American male populations. As T1 represents Argentine males and T2 American males, it can be noted that the mean, mean arterial pressure and the mean BMI of the Argentine male population is greater than those of the American male population (Figure 10). Additionally, there are significant differences in the mean habit, health and knowledge scores between the Argentine and American male populations (Figure 10). The Argentine male population has significantly lower means in habit, health and knowledge scores. These low means scores correspond to poorer health habits, health history, and health knowledge. From these two pieces of evidence, it can be inferred that populations with significantly poorer health habits, history, and knowledge will have significantly higher mean arterial pressure and BMI. Thus prevalence of poor cardiovascular health behaviors corresponds to poor cardiovascular disease risk factors. Additionally, prevalence of certain poor cardiovascular health behaviors (habit, history, and knowledge) corresponds to poor BMI, another cardiovascular health behavior. 


\subsection{Discussion}

The purpose of this study was to examine young adult cardiovascular health. In doing so, we hypothesized that young adults with low prevalence of cardiovascular health behaviors would have low prevalence of cardiovascular health risk factors. Even though not every behavior was significantly correlated with the MAP risk factor,after thorough analysis we saw that, cross-culturally, correlations exist between CV risk factors and $\mathrm{CV}$ behaviors that are consistent in both populations.Health habit, health knowledge, health history, and BMI are all significantly correlated with mean arterial pressure (Figure 2).

The AHA study found that ideal CV health is uncommon in young adult populations in the USA, Finland, and Australia by comparing the ideal CV health metrics against carotid intima thickness. While the prevalence of ideal CV health, as measured by cIMT, might be low in our populations as well, this study examined the relationship between $\mathrm{CV}$ health risk factors and CV health behaviors. The AHA study showed that there was an inverse association between ideal CV health metrics and the cIMT, thus risk factors and behaviors are associated with vascular health in the greater population [19]. By analyzing American and Argentine populations we showed that poor cardiovascular behaviors themselves are associated with poor $\mathrm{CV}$ risk factors. This is an important association because by controlling $\mathrm{CV}$ health behaviors, such as not smoking, exercising more, and maintaining a proper diet, CV risk factors can be controlled as well, leading to improved cardiovascular health.

T-tests showed that population groups with a higher CV risk factor (MAP) mean also had lower behavior means, indicating that populations with poor $\mathrm{CV}$ behaviors correlate with accumulation of $\mathrm{CV}$ risk factors (Figure 8,10). We can infer and speculate that a way to improve young adult $\mathrm{CV}$ health is to improve health habits and health knowledge, as improving health history is out of one's control.

A previous study in Brazil showed that young adults who consume a better, common Brazilian diet display healthier trends in regards to $\mathrm{CV}$ risk factors while those who have a poor, processed diet display more harmful trends. It is interesting to note that the study stated that the processed diet is similar to the Western type of diet among the American population. This included a variety of foods such as hamburgers, hot dogs, french fries, etc. In this study, diet was assessed by the consumption of fruits and vegetables, fast food, and soda [24]. Responses to diet questions were scored, in addition to other health habits, and was used to create a composite score. In the t-test analyses it was found that the American students had higher composite scores than did the Argentine students, thus the American students had healthier habits than did the Argentine students (Figure 7-10). This trend contradicts the results of the Brazilian nutrition study, however dietary components were not assessed in depth in this study as it was in the other. It is advisable to pursue this matter further and investigate the true differences in Argentine and American health habits. Consequently that type of investigation would be able to pinpoint which specific habit component affects, and to what extent, cardiovascular health.

\section{CONCLUSION}

Although we found consistency in data, there were a few anomalies that presented themselves. One major flaw: the $\mathrm{CV}$ component of heart rate. Correlation testing produced trends that we would not have expected, such as an increase in BMI correlated with a decrease in heart rate,and we are unable to accurately explain them (Figure 2,3,5,6). We hypothesize that these anomalies stem from slight errors in data collection methods. The public spaces prevented students from relaxing properly, and thus their reported heart rates were often skewed due to emotional responses to the methodology, such as anxiety. Although heart rate in the literature is not considered a cardiovascular behavior or risk factor, it was included in our study anyways because heart rate is so closely tied to function of the cardiovascular system. Due to erroneous results, we now know that we must correct methods in order to obtain more accurate data in order to investigate heart rate as a cardiovascular health indicator.

In order to more accurately pinpoint the most important behaviors that influence cardiovascular health we recommend an amended study that will analyze which specific behavior from the composite score has the most influence on $\mathrm{CV}$ health. This future study must be able to quantify young adult habits and knowledge through more in depth questioning, rather than binary questions. We realized that even though we were asking the same questions in both countries, these questions were not necessarily standardized. For example, an Argentine's perception of rigorous workout might be different than that of an American student. To better quantify our results we will need to ask more specific questions, such as "How many times per week do you engage in exercise in which your heart rate is within the target range for your age? (Age $20=$ 120-170) [25]. By using surveys with more specific questions we would be able to quantify health behaviors more precisely and thus have a range of data with which to perform in-depth statistical analysis, instead of utilizing binary data compiled into composite scores. This more in-depth analysis would allow us to pinpoint the major contributing behaviors to poor $\mathrm{CV}$ health risk factors in each country, which would allow us to 
analyze how different aspects of culture and society contribute to cardiovascular health.

In conclusion, young adults with low prevalence of cardiovascular health behaviors have low prevalence of cardiovascular health risk factors. After thorough analysis we saw that, cross culturally, correlations exist between $\mathrm{CV}$ risk factors and $\mathrm{CV}$ behaviors that are consistent in both populations. Health habit, health knowledge, health history and BMI are all significantly correlated with mean arterial pressure. T-tests showed that population groups with higher CV risk factor means also had lower behavior means, indicating that populations with poor $\mathrm{CV}$ behaviors correlate with an accumulation of $\mathrm{CV}$ risk factors. Further investigation into these behaviors with improved methodology has been proposed to pinpoint the exact differences in cardiovascular health between the young adult populations of Argentina and the United States.

\section{ACKNOWLEDGEMENTS}

We wish to thank the Natural Science Division and the Buenos Aires International Program of Pepperdine University for their support. In particular we would like to thank Dr. Lee Kats of the Natural Science Division and Rafael De Sanzo of the Buenos Aires Program. Additionally, we appreciate the cooperation of Juan Jose Herrera Paz and the residents of Instituto Sacre Coeur for their collaboration in collecting data in Buenos Aires, Argentina. We would also like to extend our appreciation to the students of both Pepperdine University andUniversidad Católica de Argentina who participated in this study.

\section{REFERENCES}

[1] Mathers C., Loncar D., "Projections of Global Mortality and Burden of Disease from 2002 to 2030", PLoS Med, vol. 3, pp. 442, 2006.

[2] May A. L., Kuklina E. V., Yoon P. W., "Prevalence of cardiovascular disease risk factors among US adolescents, 1999-2008”, Pediatrics, vol/issue: 129(6), pp. 1035-1041, 2012.

[3] Ministerio de Salud, Presidencia de la Nación", "Estadísticas Vitales - Información Básica", Secretaria de Politicas, Regulacion e Institutos. Report number: 1668-9054, 2008.

[4] Daviglus M. L., Talavera G. A., Avilés-Santa M. L., Allison M., Cai J., Criqui M. H., Gellman M., Giachello A. L., Gouskova N., Kaplan R. C., LaVange L., Penedo F., Pereira K., Pirzada A., Schneiderman N., WassertheilSmoller S., Sorlie P. D., Stamler J., "Prevalence of major cardiovascular risk factors and cardiovascular diseases among Hispanic/Latino individuals of diverse backgrounds in the United States", JAMA, vol. 308, pp. 17, 2012.

[5] Stamler J., Stamler R., Neaton J. D., Wentworth D., Daviglus M. L., Garside D., Dyer A. R., Liu K., Greenland P., "Low risk-factor profile and long-term cardiovascular and noncardiovascular mortality and life expectancy: findings for 5 large cohorts of young adult and middle-aged men and women”, JAMA, vol. 282, pp. 2012-2018, 1999.

[6] Daviglus M. L., Liu K., Pirzada A., Yan L. L., Garside D. B., Feinglass J., Guralnik J. M., Greenland P., Stamler J., "Favorable cardiovascular risk profile in middle age and health-related quality of life in older age", Archive of Internal Medicine, vol. 163, pp. 2460-2468, 2003.

[7] Lloyd-Jones D. M., Dyer A. R., Wang R., Daviglus M. L., Greenland P., "Risk factor burden in middle age and lifetime risks for cardiovascular and noncardiovascular death (Chicago Heart Association Detection Project in Industry)", American Journal of Cardiology, vol. 99, pp. 535-540, 2007.

[8] Berry J. D., Dyer A., Cai X., Garside D. B., Ning H., Thomas A., Greenland P., Van Horn L., Tracy R. P., LloydJones D. M., "Lifetime risk of cardiovascular disease", New England Journal of Medicine, vol. 366, pp. 321-29, 2012.

[9] Daviglus M. L., Liu K., Greenland P., Dyer A. R., Garside D. B., Manheim L., Lowe L. P., Rodin M., Lubitz J., Stamler J., "Benefit of a favorable cardiovascular risk-factor profile in middle age with respect to Medicare costs", New England Journal of Medicine, vol. 339, pp. 1122-1129, 1998.

[10] Daviglus M. L., Liu K., Pirzada A., Yan L. L., Garside D. B., Greenland P., Manheim L. M., Dyer A. R., Wang R., Lubitz J., Manning W. G., Fries J. F., Stamler J., "Cardiovascular risk profile earlier in life and Medicare costs in the last year of life", Archive of Internal Medicine, vol. 165, pp. 1028-1034, 2005.

[11] Lloyd-Jones D. M., Dyer A. R., Wang R., Daviglus M. L., Greenland P., "Risk factor burden in middle age and lifetime risks for cardiovascular and non-cardiovascular death (Chicago Heart Association Detection Project in Industry)", Am J Cardiol, vol. 99, pp. 535-540, 2007.

[12] Lloyd-Jones D. M., Leip E. P., Larson M. G., D’Agostino R. B., Beiser A., Wilson P. W., Wolf P. A., Levy D., "Prediction of lifetime risk for cardiovascular disease by risk factor burden at 50 years of age", Circulation, vol. 113, pp. 791-798, 2006.

[13] Stamler J., Stamler R., Neaton J. D., Wentworth D., Daviglus M. L., Garside D., Dyer A. R., Liu K., Greenland P., "Low risk-factor profile and long-term cardiovascular and noncardiovascular mortality and life expectancy: findings for 5 large cohorts of young adult and middle-aged men and women”, JAMA, vol. 282, pp. 2012-2018, 1999.

[14] Sadakane A., Tsutsumi A., Gotoh T., Ishikawa S., Ojima T., Kario K., Nakamura Y., Kayaba K., "Dietary patterns and levels of blood pressure and serum lipids in Japanese population”, Journal of Epidemiology, vol. 182, pp. 58-

IJPHS Vol. 3, No. 2, June 2014: $117-128$ 
67, 2008.

[15] Nettleton J., Polak J., Tracy R., Burke G. D. J., "Dietary patterns and incident cardiovascular disease in the multiethnic study of atherosclerosis", American Journal of Clinical Nutrition, vol. 90, pp. 647-654, 2009.

[16] Berg C., Lappas G., Strandhagen E., Wolk A., Tore'n K., Rosengren A., Aires N., Thelle D., Lissner L., "Food patterns and cardiovascular disease risk factors: the Swedish INTERGENE research program", American Journal of Clinical Nutrition, vol. 88, pp. 289-297, 2008.

[17] Tourlouki E., Matalas A., Panagiotakos D., "Dietary habits and cardiovascular disease risk in middle-aged and elderly populations: a review evidence", Clinical Interventions in Aging, vol. 4, pp. 319-330, 2009.

[18] Mikkilä V., Räsänen L., Raitakari O., Marniemi J., Pietinen P., Ro nnemaa T., Viikari J., "Major dietary patterns and cardiovascular risk factors from childhood to adulthood. The cardiovascular risk in young finns study", British Journal of Nutrition. Vol. 98, pp. 218-225, 2007.

[19] Oikonen M., Laitinen T. T., Magnussen C. G., Steinberger J., Sinaiko A. R., Dwyer T., Venn A., Smith K. J., Hutri- Kähönen N., Pahkala K., Mikkilä V., Prineas R., Viikari J. S. A., Morrison J. A., Woo J. G., Chen W., Nicklas T., Srinivasan S. R., Berenson G., Juonala M., Raitakari O. T., "Ideal Cardiovascular Health in Young Adult Populations From the United States, Finland, and Australia and Its Association With cIMT: The International Childhood Cardiovascular Cohort Consortium”, Journal of American Heart Association, vol. 2, pp. 244, 2013.

[20] Lloyd-Jones D. M., Hong Y., Labarthe D., Mozaffarian D., Appel L. J., Van H. L., Greenlund K., Daniels S., Nichol G., Tomaselli G. F., Arnett D. K., Fonarow G. C., Ho P. M., Lauer M. S., Masoudi F. A., Robertson R. M., Roger V., Schwamm L. H., Sorlie P., Yancy C. W., Rosamond W. D., "Defining and setting national goals for cardiovascular health promotion and disease reduction: the American Heart Association's strategic Impact Goal through 2020 and beyond", Circulation, vol. 121, pp. 586-613 2010.

[21] Dong C., Rundek T., Wright C. B., Anwar Z., Elkind M. S., Sacco R. L., "Ideal cardiovascular health predicts lower risks of myocardial infarction, stroke, and vascular death across whites, blacks, and hispanics: the northern Manhattan study", Circulation, vol. 125, pp. 2975-2984, 2012.

[22] Ford E. S., Greenlund K. J., Hong Y., "Ideal cardiovascular health and mortality from all causes and diseases of the circulatory system among adults in the United States", Circulation, vol. 125, pp. 987-995, 2012.

[23] Yang Q., Cogswell M. E., Flanders W. D., Hong Y., Zhang Z., Loustalot F., Gillespie C., Merritt R., Hu F. B., "Trends in cardiovascular health metrics and associations with all-cause and CVD mortality among US adults", JAMA, vol. 307, pp. 1273-1283, 2012.

[24] Olinto M., Gigante D., Jorta B., Silveira V., Oliveira I., Willett W., "Major dietary patterns and cardiovascular risk factors among Brazilian adults", European Journal of Nutrition, vol/issue: 51(3), pp. 281-291, 2012.

[25] "Pulse \& Target Heart Rate (THR)", Cleveland Clinic. 2014. http://my.clevelandclinic.org/heart/prevention/exer cise/pulse-target-heart-rate.asp\&xgt.

\section{BIOGRAPHIES OF AUTHORS}

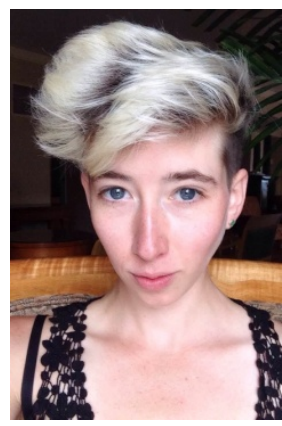

Gina Fitzgerald obtained her undergraduate Biology degree from Pepperdine University in 2013 , after having served as both a research assistant on this project and ecology research with Dr. Lee B. Kats. In addition, she worked as a teaching assistant with Dr. Stephen D. Davis in his botany lab. Her research projects have produced a presentations at Pepperdine University, Claremont Graduate University, SCCUR, and NCUR. Her volunteer work includes service in the Dominican Republic as a dental assistant, with the Instituto Sacre Coeur in Buenos Aires as a physician's assistant, and as a certified nurse's assistant at the Sunnyside Care Center in Torrance, CA. In the future, Gina plans to pursue her interest in research. She may be reached at gina.fitzgerald@pepperdine.edu.

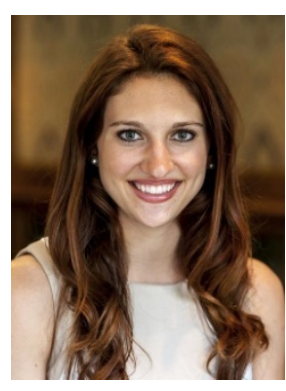

Gabriella Smith obtained her undergraduate degree in Hispanic Studies from Pepperdine University in 2014 while completing pre-medical curricula. She has participated in numerous extracurricular activities such as working at the Glazer Institute for Jewish Studies, interning at Instituto Sacre Coeur in Buenos Aires, Argentina, Christiana Care Health System in Newark, DE and Assuta Medical Center in Tel Aviv, Israel, and serving as a tutor for Pepperdine Athletics, assisting student athletes with statistics, calculus, chemistry, and biology. She has volunteered with several organizations, including the Malibu Labor Exchange, Hospital de Niños of Buenos Aires, and Relay for Life of the American Cancer Society. Next year, Gabriella plans to attend medical school. In the future she hopes to be a practicing physician and also work with nonprofit and government agencies in humanitarian and disaster relief efforts. She may be reached at gabriella.smith@pepperdine.edu. 


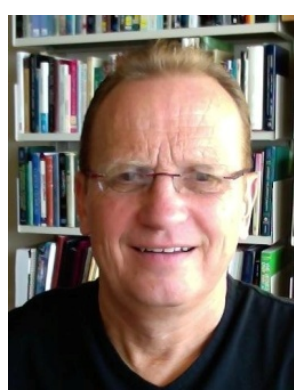

Don Thompson is Professor of Great Books \& Mathematics at Pepperdine University. He has served as a faculty member there since 1979, having earned his Ph.D. in mathematics from the University of Arizona that same year. His research interests include his ongoing work at the Hughes Research Lab in Malibu, CA on artificial neural networks and Bayesian networks, as well as working with undergraduate research students in biology, psychology, mathematics, and the great books. He may be reached at thompson@pepperdine.edu. See http://dt.pepperdine.edu for more information. 